
\title{
25 Research Soure \\ Comparison of renal safety of Telbivudine and Entecavir in Chronic Hepatitis B patients with renal impairment: A meta-analysis
}

\section{Birong Huang}

Guangxi Medical University First Affiliated Hospital https://orcid.org/0000-0003-2663-0978

\section{Shasha Ma}

Guangxi Medical University First Affiliated Hospital

Jizhou Wu ( $\nabla$ wjz925@163.com )

\section{Research}

Keywords: Chronic hepatitis B;Telbivudine, Entecavir;Nucleos(t)ide Analogues;Renal Function;

Posted Date: July 23rd, 2020

DOl: https://doi.org/10.21203/rs.3.rs-42260/v1

License: (c) (i) This work is licensed under a Creative Commons Attribution 4.0 International License. Read Full License 


\section{Abstract}

Background:This study aimed to evaluate the renal safety of telbivudine(LdT) and entecavir(ETV) in chronic hepatitis B (CHB) patients with renal impairment.

Methods:Studies published from January 1, 2010 to February 1, 2020 were identified using the PubMed, Web of Science, Scopus,Cochrane Library,ClinicalTrials.gov and CNKI (China National Knowledge Infrastructure).Finally, a total of 7 studies (1088 patients) with eGFR outcomes were retrieved and analyzed.The meta-analysis was conducted using RevMan 5.3.

Results:The results of the 7 eligible studies analyzed suggested that the eGFR was both improved after LdT and ETV treatment.Compared with the baseline level,the eGFR was significantly improved with LdT $\left(7.02 \mathrm{~mL} / \mathrm{min} / 1.73 \mathrm{~m}^{2}\right)$ while slightly improved with ETV $\left(1.72 \mathrm{~mL} / \mathrm{min} / 1.73 \mathrm{~m}^{2}\right)$ after 1 years of treatment. The eGFR was significantly higher in the LdT therapy group than in the ETV group after 6 months $(R R=4.63,95 \% \mathrm{Cl}: 0.73-8.54, \mathrm{Z}=2.33 ; \mathrm{P}=0.02) \otimes 1$ year $(\mathrm{RR}=3.35,95 \% \mathrm{Cl}: 1.18-5.52, \mathrm{Z}=3.02 ; \mathrm{P}=$ $0.002)$ \and 2 years $(R R=11.00,95 \% \mathrm{Cl}: 4.84-17.15, Z=3.50 ; P=0.0005)$ of treatment .

Conclusion: Our meta-analysis of current evidence demonstrated that in CHB patients with impaired renal function, LdT could be the better choice than ETV.

\section{Background}

Hepatitis B virus (HBV) infection is a serious public health problem all over the world, approximately 257 million persons, or $3.5 \%$ of the population, were living with chronic HBV infection worldwide[1].It is also respected to its complications, including liver cirrhosis, hepatocellular carcinoma (HCC) and liverrelated mortality[2, 3].

Treatment's primary targe in $\mathrm{CHB}$ is to prevent disease progression into serious complications by inhibiting of hepatitis B virus (HBV) DNA replication[4].To date,six nucleos(t)ide analogs(NAs) are used in $\mathrm{CHB}$ treatment,including three nucleoside analogs: lamivudine[LAM], telbivudine [LdT], and entecavir [ETV]; and three nucleotide analogs: adefovir dipivoxil [ADV],tenofovir disoproxil [TDF]and tenofovir alafenamide (TAF). These antiviral agents usually have relatively strong antiviral potency and low incidences of Resistance.However,they can also potentially cause serious adverse events, such as myopathy,neuropathy,lactic acidosis, and renal dysfunction[5].Among the adverse events, renal dysfunction is one of the risk factors, particularly in patients who already have renal impairment $[6,7]$.

Chronic HBV infection may cause renal dysfunction through immune complex-mediated glomerular diseases.As renal excretion is the primary route of elimination of the mainstay of $\mathrm{CHB}$ therapy[7],nucleos(t)ide may also induce kidney toxicity through various mechanisms.,such as renal tubular injury, apoptosis, and mitochondrial toxicity[8]. 
Due to renal function is frequently impaired in patients with compensated $\mathrm{CHB}$ and patients usually require long-term treatment[2, 8],When choosing an appropriate antiviral medicine,nephrotoxicity,which marked by a decrease in estimated glomerular filtration rate(eGFR), should be particularly considered[9].Among NAs, Telbivudine (LdT) and Entecavir (ETV) are regarded as first-line antiviral agent in CHB patients with renal impairment.

Telbivudine and entecavir are used widely to inhibit hepatitis B virus (HBV) replication. However, Data comparing renal safety of these two antiviral agents in CHB patients with renal impairment are limited and lack systematic evidence base.Therefore,the main objective of this study is collate all available evidence and summarize the data to assess the renal safety of the nucleoside analogs LdT and ETV in this specific population.

\section{Methods}

\section{Search strategy}

PubMed, Web of Science, Scopus,Cochrane Library,ClinicalTrials.gov and CNKI (China National Knowledge Infrastructure) were searched without language restriction to identify relevant articles published from January 1, 2010 to February 1, 2020. The search was performed with the following keywords:'chronic hepatitis B','telbivudine', 'entecavir','nucleos(t)ide Analogues','renal Function"estimated glomerular filtration rate', and their synonyms and related terms.

\section{Selection Criteria}

\section{The following inclusion criteria were used to select studies for review:}

1. Randomized controlled trials (RCTs), retrospective and prospective cohort studies.All studies had proper clinical information.

2. Study populations involving patients with chronic hepatitis $B$ and renal impairment [eGFR between 30 and $90 \mathrm{~mL} / \mathrm{min} / 1.73 \mathrm{~m} 2$ ], and the results contained at least eGFR outcomes.

3. The study including a LdT group or ETV group.

\section{The exclusion criteria were as follows:}

1. The patients were coinfected with either hepatitis A, C, D, or E virus or with human immunodeficiency virus (HIV)..

2. The study without sufficient information.

3. The study interventions did not include either LdT or ETV.

\section{Efficacy endpoints}

The efficacy end-point was the change in estimated glomerular filtration rate (eGFR) from baseline,which was calculated by the Modification of Diet in Renal Disease (MDRD)[10].Most studies reported the renal 
function outcomes at the time range from 6 month to 2 years follow-up,so the study efficacy endpoints were analyzed at a time point of 6 months, 1 year and 2 years.

\section{Data collection}

Two authors independently searched literature and extracted data using a predesigned data collection template, and discrepancies were discussed via discussion.The data were extracted for: (1) study characteristics:study design,year of publication,region, study type,Interventions, sample size and follow-up period.

(2) patient characteristics (age, gender) and baseline estimated glomerular filtration rate (eGFR);(3) study outcomes after treatment. The Inclusion and exclusion criteria were uniformly applied across all the publications.

\section{Risk of bias}

The Cochrane Collaboration Risk of Bias Tool was used to assess the risk of bias[11]. This tool comprised of seven criterias:(1)Random sequence generation;(2)Allocation concealment;(3)Blinding of participants and personnel;(4)Blinding of outcome assessment,(5)Incomplete outcome data;(6)Selective reporting;(7)other bias.

Three levels were used to assess the methodological quality:(1)low risk of bias;(2)high risk of bias; (3) unclear risk of bias.Assessment was independently performed by two authors, and disagreements were resolved via discussion.

\section{Data analyses}

All statistical analysis was conducted using Review Manager version 5.3 (The Cochrane Collaboration, Oxford, UK).For each eligible study, the dichotomous data were presented using the relative risk(RR) with a $95 \%$ confidence interval $(95 \% \mathrm{Cl})$, while continuous data were presented using the weighted mean difference (WMD).

The statistical heterogeneity between studies was assessed by using the chi-square $\left(\chi^{2}\right)$ and I-square $\left(I^{2}\right)$ tests., with significance set at $\mathrm{P}<0.05$,When $\mathrm{I}^{2}>50 \%, \mathrm{P}<0.05$ was considered to be statistically significant, and the random effects model was adopted for meta-analysis; otherwise,the fixed effects model was adopted[11, 12]

\section{Results}

\section{Literature search}

The study selection process is summarized in Figure 1.We identified 6102 relevant studies though database searches,After the initial screening and eligibility assessment phase, 1972 redundant publications were excluded and, after referring to the titles and abstracts, a further 41 studies that not fulfilling the inclusion criteria were rejected. The remaining 4 studies without sufficient data were rejected, 
Finally,7 studies were enrolled in this meta-analysis.Five of the articles were retrospective cohort analyse[13-17] and two was an RCTs[18, 19].A total of 1088 patients, 522 of whom were treated with LdT and 566 with ETV were included in this meta-analysis.The LdT dose used in the studies was $600 \mathrm{mg} / \mathrm{day}$ and that of ETV was $0.5 \mathrm{mg} /$ day.

\section{Study characteristics}

Table 1 summarizes the basic characteristics of the included studies and patients. Three of the included studies were from mainland, China[13, 16, 19].\{Liu, 2019 \#27;Yan, 2012 \#37;Qi, 2015 \#47\}two studies from Taiwan, China[14, 15], one studies from Korea[17] and one study from worldwide[18]. The included studies were published between 2010 and 2020. The sample size for each study ranged from 41 to 503.The mean age of the patients was 46.96 years (ranged from 38.3 to 55.2 years old). The duration of follow-up ranged from 1 year to 5 year.Male patients accounted for approximately $70.2 \%$ (ranged from $66.7 \%$ to $77 \%$ ) of all patients. Two publications $[14,15]$ reported by the same first author were confirmed not to overlap due to the use of different study periods,so they were included in the study.

\section{Table 1 Characteristics of included studies}

\begin{tabular}{|c|c|c|c|c|c|c|}
\hline $\begin{array}{l}\text { Study } \\
\text { Design }\end{array}$ & Year Region & $\begin{array}{ll}\text { Study } & \text { Interventions } \\
\text { type } & \end{array}$ & Sample size & $\begin{array}{l}\text { Men sex } \\
(\%)\end{array}$ & $\begin{array}{l}\text { Agea } \\
\text { (years) }\end{array}$ & $\begin{array}{l}\text { Follow-up } \\
\text { period }\end{array}$ \\
\hline Liu et al. & 2020 China & Cohort LdT/ETV & LdT: 21 ETV:20 & $66.7 \%$ & 38.25 & 1.5 years \\
\hline $\begin{array}{l}\text { Tsai et } \\
\text { al. }\end{array}$ & 2016 Taiwan & CohortLdT/ETV/TDF & LdT:42 ETV:62 TDF037 & $77 \%$ & 55.2 & 2 years \\
\hline
\end{tabular}

Tsai et 2015 Taiwan $\quad$ Cohort LdT/ETV/TDF $\quad$ LdT:79 ETV:119 TDF075 $\quad 71.7 \% \quad 52.9 \quad 5$ years
al.

X. Qi et 2015 China

al.
Cohort LAM/ADV/LdT/ETVLAM:11 ADV:17 LdT:8 ETV: 73\% 20 Untreated:6
$42 \quad 2$ years

\begin{tabular}{|c|c|c|c|c|c|c|c|}
\hline $\begin{array}{l}\text { Lee et } \\
\text { al. }\end{array}$ & 2015 Korea & Coho & LdT/ETV & LdT: 61 ETV: 310 & $67.0 \%$ & 53.8 & 1.5 years \\
\hline $\begin{array}{l}\text { Gane et } \\
\text { al. }\end{array}$ & 2013 Worldwide & RCT & LdT/LAM & LdT: 261 LAM: 242 & NA & NA & 2 years \\
\hline Han et al & 2012 China & RCT & LdT/ETV/ADV & LdT: 50 ETV:35 ADV:30 & $69 \%$ & 39.6 & 1 year \\
\hline
\end{tabular}


ADV adefovir, ETV entecavir, LdT telbivudine, TDF tenofovir, RCT randomized controlled trial,N/A not applicable

\section{Changes in eGFR with LdT therapy}

Six included studies,involving 514 patients, reported the change in eGFR after 1 year of LdT treatment (Fig. 2). The results showed that the eGFR was improved by $7.02 \mathrm{~mL} / \mathrm{min} / 1.73 \mathrm{~m} 2$ with LdT after 1 year of treatment. There was statistical heterogeneity was observed among these studies $\left(\mathrm{I}^{2}=85 \%, \mathrm{P}<\right.$ $0.00001)$ with a random-effects model. The result indicated a statistically significant change in the eGFR significant $(\mathrm{RR}=7.02,95 \% \mathrm{Cl}: 2.69-11.35, \mathrm{Z}=3.17 ; \mathrm{P}=0.001)$.

\section{Changes in eGFR with ETV therapy}

Five included studies, including 546 patients,investigated the change in eGFR after 12 months of treatment with ETV (Fig. 3). The results showed that the eGFR was slightly increased after ETV treatment compared with baseline $(1.72 \mathrm{~mL} / \mathrm{min} / 1.73 \mathrm{~m} 2)$, and there was no significant heterogeneity among these studies $\left(I^{2}=43 \%, P=0.14\right)$ with a fixed-effect model. The overall test result indicated that the eGFR was slightly increased after 12 months of treatment with $\operatorname{ETV}(\mathrm{RR}=1.72,95 \% \mathrm{Cl}: 0.09-3.35, \mathrm{Z}=2.07 ; \mathrm{P}=$ 0.04).

\section{Renal safety comparison between LdT therapy group and ETV therapy group}

There is no significant differences in baseline demographic data (age, gender) and eGFR level between the study groups. Two studies comprising 412 patients reported the change in eGFR after 6 months of treatment,as shown in Figure 4a,The eGFR was significantly higher in the LdT therapy group than in the ETV group after 6 months $(R R=4.63,95 \% \mathrm{Cl}: 0.73-8.54, Z=2.33 ; \mathrm{P}=0.02)$. and there was no significant heterogeneity among these studies $\left(I^{2}=0 \%, P=0.95\right)$ with a fixed-effect model. Five studies comprising 788 patients reported the change in eGFR after 1 year of treatment,as shown in Figure 4b,The eGFR was significantly higher in the LdT therapy group than in the ETV group after 1 year $(\mathrm{RR}=3.35,95 \% \mathrm{Cl}$ : $1.18-$ $5.52, Z=3.02 ; P=0.002)$. and there was no significant heterogeneity among these studies $\left(I^{2}=0 \%, P=\right.$ 0.82 ) with a fixed-effect model.Three studies comprising 284 patients reported the change in eGFR after 2 year of treatment,as shown in Figure 4c,The eGFR was significantly higher in the LdT therapy group than in the ETV group after 2 year $(R R=11.00,95 \% \mathrm{Cl}: 4.84-17.15, Z=3.50 ; P=0.0005)$.and there was significant heterogeneity among these studies $\left(I^{2}=53 \%, P=0.12\right)$ with a random-effects model. The changes trends in eGFR during treatment in the LdT and ETV groups are shown in Fig.5.

\section{Risk of bias}

All trials were evaluated by the Cochrane Collaboration's risk-of-bias tool.The risk of bias assessment conducted for each study included is presented in Fig. 6. 


\section{Discussion}

Renal function is an important prognostic factor in CHB patients.Amet et al reported that $64.6 \%$ of patients were found to have renal abnormalities by international definition[20].The study by Raquel et al demonstrated that the percentage of Renal and urinary disorders with LAM,ETV,LdT,ADV,TDF,and TAF were $0.02 \% 1.6 \%, 0.1 \%, 0.4 \%, 6.8 \%$ and $11.1 \%[21]$.The risk factors for renal abnormalities include aging,gender,smoking,alcohol intake,diabetes,hypertension,anaemia and dyslipidaemia[20, 22, 23].so they recommend appropriate on-treatment monitoring of renal function[20].All currently available NAs are primarily predominantly eliminated unchanged in urine.These oral Antiviral agents,especially the nucleotide analogs, are associated with a dose-dependent nephrotoxicity, and both of pre-existing renal insufficiency and concomitant nephrotoxic agents are considered to be the risk factors of nephrotoxicity[24].Therefore,Special attention should be given to patients with pre-existing renal insufficiency who have been treated with Nucleos(t)ide Analogues,because they have a high tendency to develop renal dysfunction during prolonged $\mathrm{CHB}$ therapy[25].

We found that there's significant difference in comparing telbivudine with entecavir from 6 months to two years follow up period.Previous studies indicated that the improvement in eGFR was maintained longterm in telbivudine therapy[16, 18].However,the mechanism by which telbivudine therapy improves renal function is still under investigation,it perhaps due to suppress ACE levels, which can control reninangiotensin aldosterone regulatory system and affect systemic vasoconstriction and renal sodium and renal fluid retentions.Liang et al. reported that after about 1 year telbivudine treatment,Patients' eGFR was found significant increase. The serum angiotensin converting enzyme levels were negatively correlated with eGFR $(r=-0.375, p=0.002)$.Significant decreases of the serum angiotensin converting enzyme levels were also observed upon entecavir treatment,but no significant correlation was found between serum serum angiotensin converting enzyme levels and eGFRs $(r=-0.239, P=0.138)[26]$.

Some previous studies reporting that there was no obvious difference in mean eGFR among patients treated with entecavir[24, 27],some studies indicated that eGFR in CHB patients improved signifificantly after entecavir treatment,specially in renal patients[14, 15].Mandíková J demonstrates that the potency of ETV to cause nephrotoxicity and/or clinically significant drug-drug interactions related to the tested transporters is considerably lower than that of nucleotide analogs[9]. One thing for sure is that the ETVtreated did not deteriorate significantly compared to baseline.

Tenofovir disoproxil fumarate (TDF), a prodrug of tenofovir,has been shown to have a potential nephrotoxic[25]凶There is also study found that patients treated with TDF were not associated with renal impairment than patients treated with entecavir,but pre-existing renal insufficiency can increase the risk of developing changes in renal function[28]. However,tenofovir alafenamide(TAF), a new tenofovir salt formulation,was shown to have better renal and bone safety than TDF[29],can be used as a replacement drug.Patients who have been treated with TDF,especially in who with a baseline eGFR of below $90 \mathrm{~mL} / \mathrm{min}$,can swich TAF to improve renal function[29, 30]. However,the number of patients receiving with TAF is too small to consolidate that TAF has a less impact on renal function than TDF. 
There were none of network Meta-analysis published focusing on renal safety of antiviral therapy of CHB patients with renal impairment.Also,there were several limitations in this study.First,the numbers of studies were modest,only seven researches were included in the meta-analysis,and the number of prospective studies is also limited.Second,most studies were retrospective cohort studies and observational,with only two RCT, so there is an increased selection bias risk in retrospective studies.Third,eGFR was evaluated after only 2 year. As the duration of treatment of patients with $\mathrm{CHB}$ is several years, the clinical significance of the reported eGFR changes needs further elucidation.Finally, the participants covered in our meta-analysis are mainly from Asian countries, where the prevalence of HBV infection is high,and this might limit the generalizability of the results to multiple ethnicities.

\section{Conclusions}

In conclusion,this meta-analysis current evidence demonstrated that compared with ETV therapy,LdT has a significant improvement in eGFR in CHB patients with renal impairment.Patients with renal impairment in particular benefited from telbivudine therapy.So in these patiens,LdT could be the better choice than ETV.

\section{Abbreviations}

CHB: chronic hepatitis;LDT: telbivudine;ETV: entecavir;;CNKI:China National Knowledge Infrastructure;HBV:Hepatitis B virus;HCC:hepatocellular carcinoma;NAs:nucleos(t)ide analogs;LAM:lamivudine;ADV: adefovir dipivoxil;TDF:,tenofovir disoproxil; TAF:tenofovir alafenamide;eGFR: estimated glomerular filtration rate;RCTs:Randomized controlled trials;HIV:human immunodeficiency virus;MDRD:Modification of Diet in Renal Disease;

\section{Declarations}

\section{Acknowledgements}

Not applicable.

\section{Authors' contributions}

BH planned the study.BH and SM collected intellectual materials \analyzed the data and drafted the manuscript. JW was involved in revising the manuscript. All authors read and approved the final manuscript.

\section{Competing interests}

The authors declare that they have no competing interests.

\section{Funding}


This work was supported by the Chinese National Natural Science Foundation(30960170).

Availability of data and materials

The data used to support the findings of this study are included in this published article.

Ethics approval and consent to participate

Not applicable.

\section{Consent for publication}

All authors approved the manuscript for publication.

\section{Author details}

*Department of Infectious Diseses, The First Affiliated Hospital,Guangxi Medcal University,Nanning,530021,China.

\section{References}

1. Global hepatitis report 2017 [ http://www.who.int/iris/handle/10665/255016].

2. Cho EJ, Kim SE, Suk KT, An J, Jeong SW, Chung WJ, Kim YJJC. hepatology m: Current status and strategies for hepatitis B control in Korea. 2017, 23:205.

3. WHO Fact. Sheet on Hepatitis B http://www.who.int/mediacentre/factsheets/fs204/en/.

4. Lo OS. Wong LHJERoG, Hepatology: Current developments in nucleoside/nucleotide analogues for hepatitis B. 2014, 8:607-622.

5. Fung J, Seto WK, Lai CL. Yuen MFJJog, hepatology: Extrahepatic effects of nucleoside and nucleotide analogues in chronic hepatitis B treatment. 2014, 29:428-434.

6. Pipili C, Cholongitas E. Papatheodoridis GJAp, therapeutics: nucleos $(\mathrm{t})$ ide analogues in patients with chronic hepatitis B virus infection and chronic kidney disease. 2014, 39:35-46.

7. Chan HL, Shaikh J, Gupta S, Hamed KJAit. Renal function in nucleos $(t)$ ide analog-treated patients with chronic hepatitis B: a systematic literature review and network meta-analysis. 2016, 33:862875.

8. Wu X, Cai S, Li Z, Zheng C, Xue X, Zeng J, Peng, JJVj: Potential effects of telbivudine and entecavir on renal function: a systematic review and meta-analysis. 2016, 13:64.

9. Mandíková J, Volková M, Pávek P, Navrátilová L, Hyršová L, Janeba Z, Pavlík J, Bárta P. Trejtnar FJFip: Entecavir interacts with influx transporters hOAT1, hCNT2, hCNT3, but not with hOCT2: the potential for renal transporter-mediated cytotoxicity and drug-drug interactions. 2016, 6:304.

10. Wu MT, Lam KK, Lee WC, Hsu KT, Wu CH, Cheng BC, Ng HY, Chi PJ, Lee YT, Lee CTJJocla. Albuminuria, proteinuria, and urinary albumin to protein ratio in chronic kidney disease. 2012, 26:82- 
92.

11. Higgins J, Green S. Cochrane Handbook for Systematic Reviews of Interventions, Version 5.1.0. The Cochrane Collaboration. 2013.

12. Dersimonian R, Nan LJCCT. Meta-Analysis in Clinical Trials. 1986, 7:177-188.

13. Liu B, Shen B, Mei M, Li L, Wang X, Apheresis HZJT, Dialysis. Potential Effects of Telbivudine Versus Entecavir on Renal Function in Patients With Chronic Hepatitis B Virus Receiving Glucocorticoids Therapy. 2019, 24:56-63.

14. Tsai MC, Chen $\mathrm{CH}$, Tseng PL, Hung $\mathrm{CH}$, Chiu KW, Chang KC, Yen YH, Lin MT, Hu THJPO. Does Nucleos(t)ide Analogues Treatment Affect Renal Function in Chronic Hepatitis B Patients Who Have Already Decreased eGFR? A Longitudinal Study. 2016, 11:e0149761.

15. Tsai M-C, Chen C-H, Tseng P-L, Hung C-H, Chiu K-W, Wang J-H, Lu S-N, Lee C-M, Chang K-C, Yen YHJCM, Infection: Comparison of renal safety and efficacy of telbivudine, entecavir and tenofovir treatment in chronic hepatitis B patients: real world experience. 2016, 22:95. e91-95. e97.

16. Qi X, Wang JY, Mao RC, Zhang JMJJVH. Impact of nucleos(t)ide analogues on the estimated glomerular filtration rate in patients with chronic hepatitis B: a prospective cohort study in China. 2015, 22:46-54.

17. Lee S, Park JY, Song K, Kim DY, Kim BK, Kim SU, Ku HJ, Han KH, Sang HAJG. Liver: Comparison of the Effects of Telbivudine and Entecavir Treatment on Estimated Glomerular Filtration Rate in Patients with Chronic Hepatitis B. 2015, 9:776-783.

18. Gane EJ, Deray G, Liaw Y-F, Lim SG, Lai C-L, Rasenack J, Wang Y, Papatheodoridis G, Di Bisceglie A, Buti MJG. Telbivudine improves renal function in patients with chronic hepatitis B. 2014, 146:138146. e135.

19. Yan J-q, Han TJSMJ. Impact of nucleoside analogues on glomerular filtration rate in patients with chronic hepatitis B. 2012, 52:11-13.

20. Amet S, Bronowicki JP, Thabut D, Zoulim F, Bourliere M, Mathurin P, De Ledinghen V, Benhamou Y, Larrey DG, Janus NJLI. Prevalence of renal abnormalities in chronic HBV infection: The HARPE study. 2015, 35:148-155.

21. Fraga RSd, Vaisberg VV, Mendes LCA, Carrilho FJ, Gastroenterology SKOJJo. Adverse events of nucleos(t)ide analogues for chronic hepatitis B: a systematic review. 2020:1-19.

22. Chacko EC, Surrun SK, Mubarack Sani TP, Pappachan JMJPMJ. Chronic viral hepatitis and chronic kidney disease. 2010, 86:486-492.

23. Prowpanga U, Donghee, Kim. Aijaz, Ahmed, pharmacology RJA, therapeutics: Longitudinal trends in renal function in chronic hepatitis B patients receiving oral antiviral treatment. 2018.

24. Lai-Hung WG, Lik-Yuen CH, Yee-Kit T, Cheuk-Fung YT, Long-Yan LK, Chung-Yan LG, Cheuk-Chun S, Pharmacology WVW-SJA, Therapeutics: Chronic kidney disease progression in patients with chronic hepatitis B on tenofovir, entecavir, or no treatment. 2018. 
25. Lee M, Oh S, Lee HJ, Yeum TS, Kim YJJJoVH. Telbivudine protects renal function in patients with chronic hepatitis B infection in conjunction with adefovir-based combination therapy. 2013, 21:873881.

26. Liang KH, Chen YC, Hsu CW, Chang ML, Yeh CTJHM. Decrease of Serum Angiotensin Converting Enzyme Levels Upon Telbivudine Treatment for Chronic Hepatitis B Virus Infection and Negative Correlations Between the Enzyme Levels and Estimated Glumerular Filtration Rates. 2014, 14.

27. Tsai MC, Chen CH, Hu TH, Lu SN, Lee CM, Wang JH, Hung CHJJotFMA: Long-term outcomes of hepatitis B virus-related cirrhosis treated with nucleos(t)ide analogs. 2017, 116:512.

28. Gish RG, Clark MD, Kane SD, Shaw RE, Baqai SJCG. Hepatology: Similar Risk of Renal Events Among Patients Treated With Tenofovir or Entecavir for Chronic Hepatitis B. 2012, 10:941-946; quiz e968.

29. Chan H, Seto W, Buti M, Izumi N, Lim Y, Kao J, Streinu-Cercel A, Nurmukhametova E, Ma X, Tabak F: Bone and renal safety are improved in chronic hbv patients 1 year after switching to tenofovir alafenamide (TAF) from tenofovir disoproxil fumarate (TDF). 2019.

30. Bernard S, Bruno L, Alexandra C, Matthias C, F GH, Helen K, Marcel S, Enos B, Patrick S. Diseases FCAJTJol: Changes in Renal Function After Switching From TDF to TAF in HIV-Infected Individuals: A Prospective Cohort Study. 2020.

\section{Figures}

6102 of records identified through database searching

0 of additional records identified through other sources

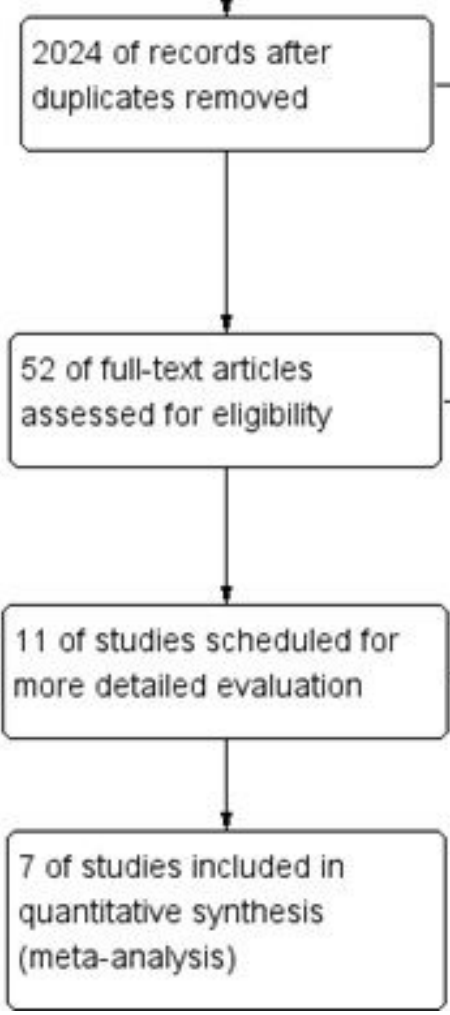
not fulfilling the inclusion criteria and excluded sufficient data and 
Figure 1

Flow chart of study selection for the meta-analysis.

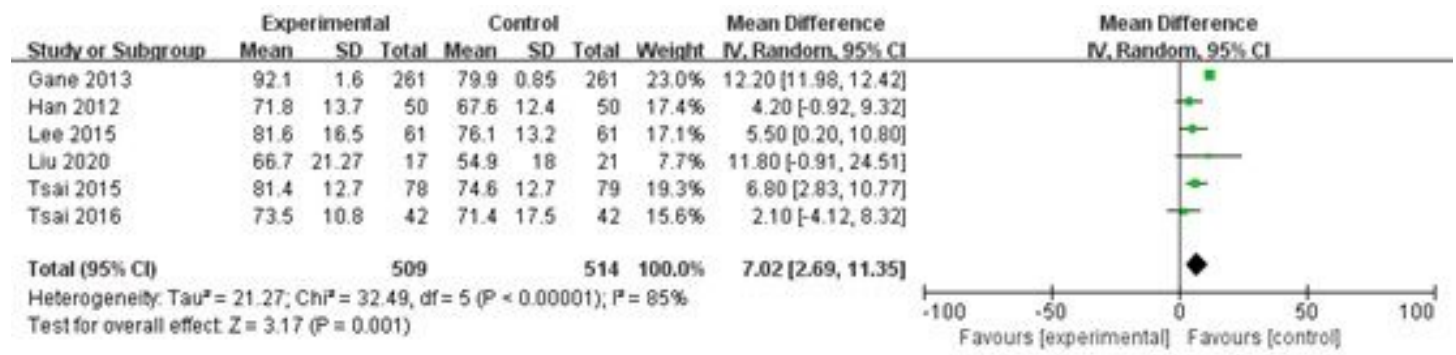

\section{Figure 2}

The change in eGFR after 1 year of telbivudine treatment

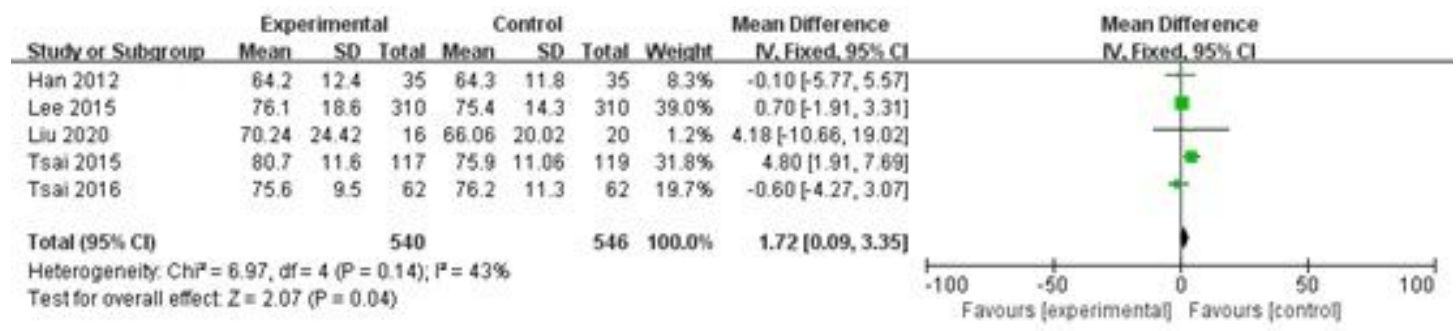

\section{Figure 3}

The change in eGFR after 1 year of entecavir treatment 
(a)

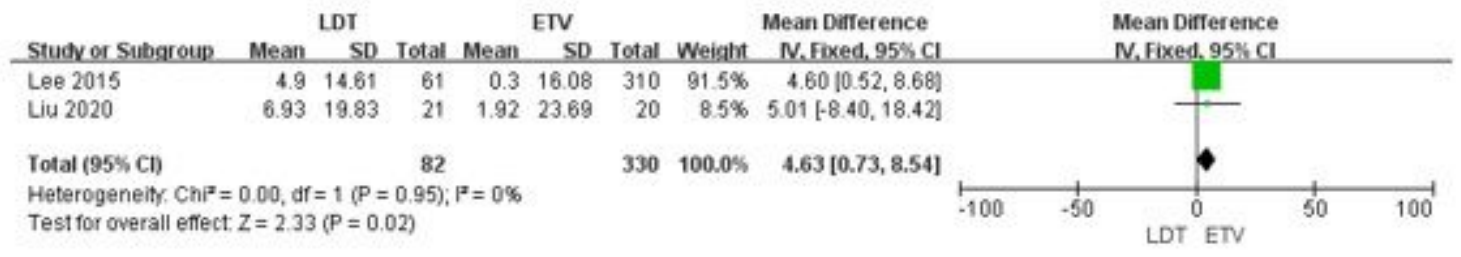

(b)

\begin{tabular}{|c|c|c|c|c|c|c|c|c|c|c|c|}
\hline \multirow[b]{2}{*}{ Studv or Subgroup } & \multicolumn{3}{|c|}{ LDT } & \multicolumn{3}{|c|}{ ETV } & \multicolumn{3}{|c|}{ Mean Difference } & \multirow{2}{*}{\multicolumn{2}{|c|}{$\begin{array}{l}\text { Mean Difference } \\
\text { N. Fixed, } 95 \% \mathrm{Cl}\end{array}$}} \\
\hline & Mean & SD & Total & Mean & SD & Iotal & Weight & N. Fixed, $95 \% \mathrm{Cl}$ & & & \\
\hline Lee 2015 & 5.5 & 15.12 & 61 & 0.7 & 16.87 & 310 & $26.3 \%$ & $4.80[0.57,9.03\}$ & & + & \\
\hline Tsai 2015 & 6.8 & 12.7 & 78 & 4.8 & 11.34 & 117 & $38.7 \%$ & $2.00[-1.49,5.49]$ & & 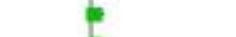 & \\
\hline Tsai 2016 & 2.1 & 15.29 & 42 & .0 .6 & 10.52 & 62 & $16.7 \%$ & $2.70[-2.61,8.01]$ & & $\rightarrow$ & \\
\hline
\end{tabular}

(c)

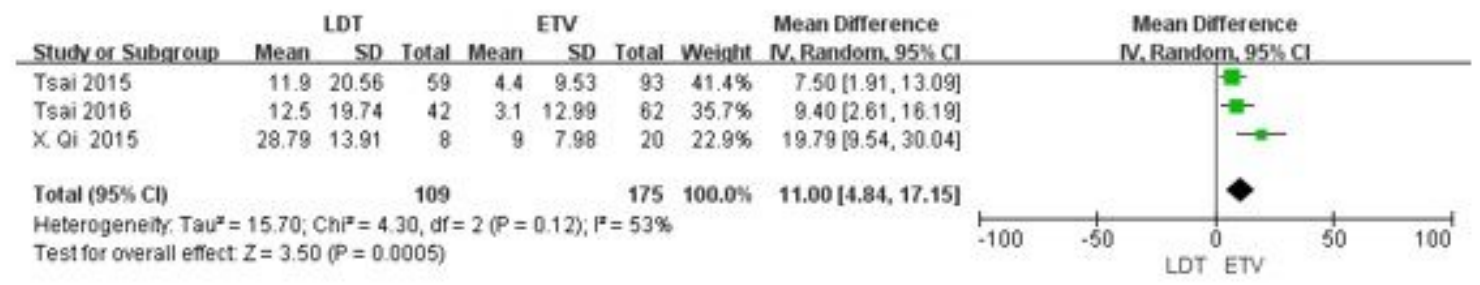

\section{Figure 4}

(a)The change in eGFR after 6 months of treatment comparing telbivudine with entecavir;(b)The change in eGFR after 1 year of treatment comparing telbivudine with entecavir;(c)The change in eGFR after 2 years of treatment comparing telbivudine with entecavir 
(a)

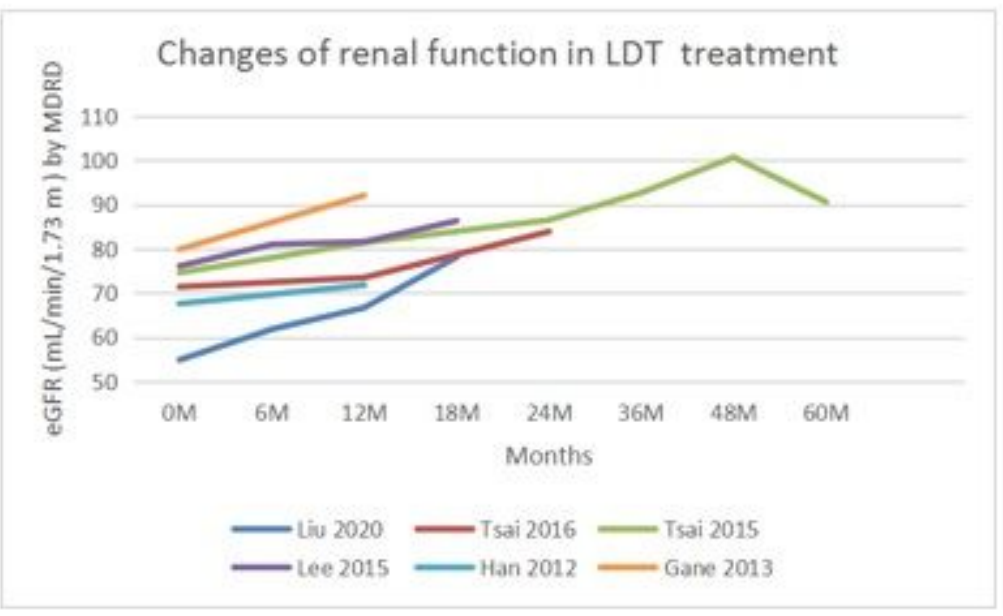

(b)

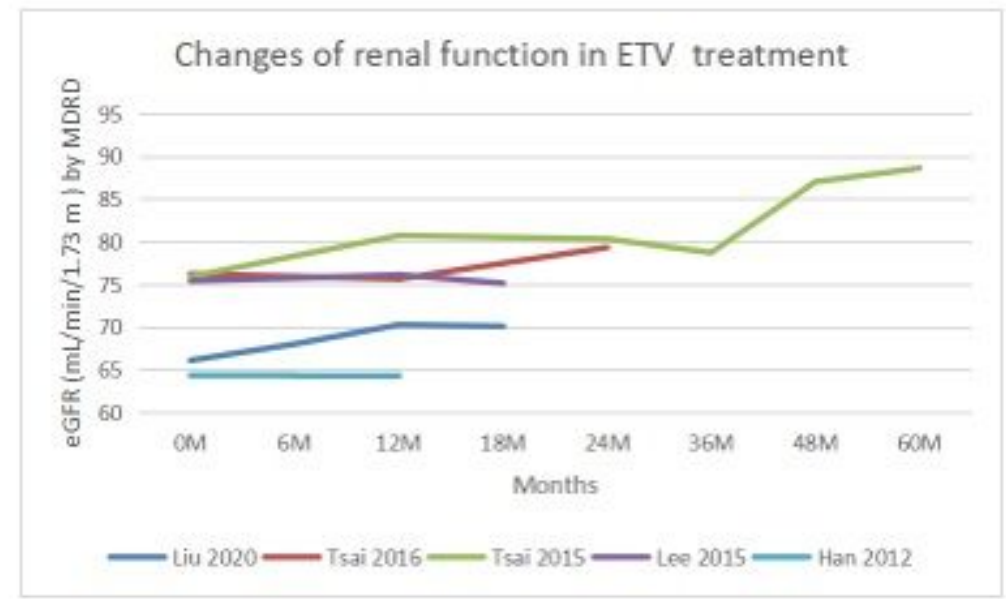

Figure 5

囚a $\mathrm{XThe}$ changes trends of renal function during treatment in the LdT;(b)The changes trends renal function during treatment in the ETV. 